\title{
Antihyperlipidemic Effects of Red Ginseng, Crataegii Fructus and Their Main Constituents Ginsenoside Rg3 and Ursolic Acid in Mice
}

\author{
Sung-Won MiN1, Sang-Hyun JunG ${ }^{2}$, Ki-Ho $\mathrm{CHO}^{2}$ and Dong-Hyun $\mathrm{KIm}^{1}{ }^{1,}$ \\ ${ }^{1}$ College of Pharmacy, Kyung Hee University, 1, Hoegi, Dongdaemun-ku, Seoul 130-701, Republic of Korea \\ ${ }^{2}$ School of Korean Medicine, Kyung Hee University, 1, Hoegi, Dongdaemun-ku, Seoul 130-701, Republic of Korea
}

(Received October 12, 2008; Revised October 31, 2008; Accepted November 1, 2008)

\begin{abstract}
Anti-hyperlipidemic effect of red ginseng (RG; the steamed root of Panax ginseng C.A. Meyer) and Crataegii fructus (CF, the fruit of Crataegus pinnatifida BGE), which are used frequently in China and Korea as herbal medicines to treat arteriosclerosis, were investigated. Treatments of RG and CF significantly reduced blood triglyceride (TG) and total cholesterol (TC) levels in Triton WR-1339-induced hyperlipidemic mice and serum TG levels in corn oil-induced hypertriglyceridemic mice. Ginsenoside Rg3 and ursolic acid, the main constituents of $R G$ and $C F$, respectively, also reduced $T G$ and $T C$ levels in hyperlipidemic mice. RG and CF significantly lowered the high blood TG and TC levels and body and epididymal mass weights induced by long-term feeding of a high-fat diet and increased the high-fat diet-induced decrease in blood HDL cholesterol levels. RG and $\mathrm{Rg} 3$ reduced the blood TC levels more than CF and ursolic acid. However, blood TG level were reduced by $\mathrm{CF}$ and ursolic acid more than RG and Rg3. RG, CF, and their constituents also inhibited pancreatic lipase and HMG-CoA reductase activities. The most potent inhibitor was Rg3. These findings suggest that RG and CF may be suitable for the therapies of hypercholesterolemia and triglyceridemia, respectively.
\end{abstract}

Keywords: Red ginseng, Crataegus pinnatifida, Hyperlipidemia, Pancreatic lipase, HMG-CoA reductase, Ginsenoside Rg3, Ursolic acid

\section{INTRODUCTION}

Lipid metabolism normally maintains an elegant balance between synthesis and degradation. When this balance is lost, hypercholesterolemia and hyperlipidemia may develop, leading to arteriosclerosis, hypertension, obesity, diabetes, and functional depression of select organs (Goldstein et al., 1973). The rate-limiting enzyme of cholesterol biosynthesis from acetate is HMG-CoA reductase (Heller and Shrewsburg, 1976; White and Rudney, 1970). Pancreatic lipase is a key enzyme for lipid breakdown and fatty acid absorption (Birari and Bhutani, 2007). Inhibitors of pancreatic lipase or HMG-CoA reductase are anti-hypercholesterolemic agents (Birari and Bhutani, 2007; Endo et al., 1992; Davidson, 2003), such as orlistat and lovastatin, and reduce the absorption of dietary triglycerides and inhibit cholesterol biosynthesis, respectively. However, repeated use of these agents

\section{${ }^{*}$ Corresponding author}

Tel: +82-2-961-9230,

E-mail: dhkim@khu.ac.kr causes side effects (Davidson, 2003; Ballinger, 2000). Thus, herbal medicines have been receiving increased attention as alternative treatments for hyperlipidemia (Zhou et al., 2005).

Red ginseng (RG), which is the steamed root of Panax ginseng CA Meyer, showed hypolipidemic effects in cyclophosphomide- and Triton WR-1339-induced mice (Trinh et al., 2007; Inoue et al., 1999). Its main ingredients, the ginsenosides Rg3 and Rh2, reduced blood TG and TC levels in triton WR-1339-induced hyperlipidemic mice (Trinh et al., 2007). Crataegii fructus (CF, the fruit of Crataegus pinnatifida BGE) also showed antihyperlipidemic effects in rats and humans (Chang et al., 2005; la Cour et al., 1995). Its main constituent, ursolic acid, reduced blood TC levels in experimental arteriosclerosis in rats and rabbits (Liu, 1995). Nevertheless, their antihyperlipidemic mechanism has not been thoroughly studied.

Therefore, to understand their antihyperlipidemic effects, we investigated the hypolipidemic effects of $R G$, $\mathrm{CF}$, and their main constituents, ginsenoside Rg3 and ursolic acid, on corn oil, Triton WR-1336 and high fatinduced experimental hyperlipidemic mice. 


\section{MATERIALS AND METHODS}

\section{Materials}

Triton WR-1339, tributyrin, PL, ursolic acid, and lovastatin were purchased from Sigma Chemical (St. Louis, MO, USA). Total cholesterol and triglyceride assay kits were purchased from Asan Pharmaceutical Co. Ltd. (Korea). Orlistat (Xenical) was kindly donated by Dr. B W Song of Kyung Hee Medical Center, Kyung Hee University (Seoul, Korea). A high-fat diet containing 25\% beef tallow [American Institute of Nutrition (AiN)-76 fat-diet \#180337] was purchased from Dyets, Inc. (Bethlehem, PA, USA).

$R G$ and CF were purchased from Kyung Dong Market (Seoul, Korea) and identified by Dr. Nam-Je Kim, EastWest Medical Research Institute, Kyung Hee Medical Center, Kyung Hee University. The ginsenoside, Rg3, was isolated from RG as previously described (Trinh et al., 2007).

\section{Extraction of RG and CF}

$R G(500 \mathrm{~g})$ or CF $(500 \mathrm{~g})$ were extracted twice with $5 \mathrm{~L}$ of boiling water, filtered, evaporated in a rotary vacuum evaporator, and freeze-dried. The yields were $23.9 \%$, $20.2 \%$, and $22.3 \%$, respectively. The main component of each extract was analyzed using a Younglin HPLC system (Younglin instrument, Korea). The sample extracts were subjected to Develosil C30-UG-5 $(4.6 \times 250 \mathrm{~mm}, 5$ $\mu \mathrm{m}$, Nomura Chem. Co. Ltd., Japan). The mobile phase was water (solvent A) and acetonitrile. Gradient elutions were performed as follows: solvent $B$ increasing from $0 \%$ to $100 \%$ in $20 \mathrm{~min}$ and then held at $100 \%$ for $5 \mathrm{~min}$. The injected volume was $20 \mu \mathrm{L}$, the flow rate was $1 \mathrm{~mL} / \mathrm{min}$, and the UV absorbance was monitored at $203 \mathrm{~nm}$. The contents of ursolic acid in CF extract and Rg3 in RG extract were $0.68 \%$ and $0.27 \%$, respectively.

\section{Assay of PL activity}

The enzyme activity assay was performed according to a previously reported method. (Bae et al., 2002). The reaction mixture $(3.06 \mathrm{~mL})$ contained $135 \mathrm{mM}$ triolein emulsified in gum acacia, $2 \mathrm{mM}$ sodium thioglycolate, and $\mathrm{PL}$ (0.6 $\mathrm{U}$ using triacetin as a substrate), adjusted to $\mathrm{pH}$ 8.8 with $0.1 \mathrm{M} \mathrm{NaOH}$, incubated at $25^{\circ} \mathrm{C}$, and adjusted to $\mathrm{pH} 8.8$ with $10 \mathrm{mM} \mathrm{NaOH}$. The inhibitory activity of the sample was calculated from the titrated volume.

\section{Assay of HMG-CoA reductase activity}

HMG-CoA reductase was partially purified according to the method of Edwards et al. (1980). Male Sprague-Daw- ley rats (250-300 g body weight) were housed one per cage in a room where the lights were off from 7:00 AM to 7:00 PM. Food and water were available ad libitum. For 3 days prior to killing, the rats were fed powdered rat chow containing $5 \%$ cholestyramine. Animals were killed at 1:00 PM, the peak of the HMG-CoA reductase cycle. The livers were homogenized at $4^{\circ} \mathrm{C}$ in $25 \mathrm{~mL}$ buffer $\mathrm{A}(0.1 \mathrm{M}$ sucrose, $0.05 \mathrm{M} \mathrm{KCl}, 0.04 \mathrm{M}$ potassium phosphate, and $0.03 \mathrm{M}$ potassium EDTA; $\mathrm{pH} 7.2$ ) with a motor-driven, tight-fitting, glass-Teflon Potter-Elvejhem homogenizer, and microsomes were prepared. Three-milliliter aliquots of the microsomal suspension were frozen in glass tubes at a rate of $6-8^{\circ} \mathrm{C}$ per min unless otherwise stated, and stored at $-20^{\circ} \mathrm{C}$ for up to 2 months. For optimal solubilization of the reductase, the frozen microsomes were allowed to thaw to $37^{\circ} \mathrm{C}$ before addition of an equal volume of $50 \%$ glycerol in buffer B (buffer A plus $10 \mathrm{mM}$ DTT) preheated to $37^{\circ} \mathrm{C}$. The suspension was rehomogenized with 10 downward passes of a hand-driven, allglass Potter-Elvehjem homogenizer and then incubated at $37^{\circ} \mathrm{C}$ for $60 \mathrm{~min}$. The suspension was diluted threefold with buffer $\mathrm{B}$ heated to $37^{\circ} \mathrm{C}$ for a final glycerol concentration of $8.3 \%$, rehomogenized with 10 downward passes of the glass homogenizer pestle, and centrifuged at $100,000 \times \mathrm{g}$ for $60 \mathrm{~min}$ at $25^{\circ} \mathrm{C}$. The supernatant containing solubilized HMG-CoA reductase was used for the enzyme inhibitory activity assay as the crude enzyme.

The inhibitory activity assay of HMG-CoA reductase was performed according to the method of Edwards et al. (1979). Its activity was determined at $37^{\circ} \mathrm{C}$ in a total volume of $0.5 \mathrm{~mL}$ using a Beckman spectrophotometer (Shimazu). The cell path length was $1.0 \mathrm{~cm}$. The oxidation rate of NADPH was initially determined in the absence of HMG-CoA, and this blank value was subtracted from the rate obtained with both substrates. The activity assay reaction mixture contained $0.2 \mathrm{M} \mathrm{KCl}, 0.16 \mathrm{M}$ potassium phosphate, $0.004 \mathrm{M}$ EDTA, and $0.001 \mathrm{M}$ DTT, $0.2 \mathrm{mM}$ $\mathrm{NADPH}$, and 0.1 M RS-HMG-CoA; pH 6.8.

\section{Animals}

Male ICR mice (20-25 g) were purchased from Orient Charles River Co. (Korea) and fed a commercial diet (Orient Charles River Co., Korea). These animals were kept for at least 7 days prior to the experiments. All animals were housed in wire cages at $20-22^{\circ} \mathrm{C}, 50 \% \pm 10 \%$ humidity, fed standard laboratory chow (Samyang, Seoul, Korea), and allowed water ad libitum. All procedures relating to animals and their care conformed to the international guidelines 'Principles of Laboratory Animals Care' (NIH publication no. 85-23 revised 1985). 
To evaluate hypolipidemic effects, three kinds of hyperlipidemic animal models were established. First, a hyperlipidemic mouse model based on corn oil was established according to the method of Duhault et al. (1976). Six mice were used per group. Corn oil $(1 \mathrm{~g} / \mathrm{kg})$ was orally administered $2 \mathrm{~h}$ after each sample was administered orally. Two hours after the administration of corn oil, blood samples of the mice were drawn by cardiac puncture under ether anesthesia. Second, a hyperlipidemic mouse model based on Trition WR-1339 was established according to the method of Kusama et al. (1988). Triton WR-1339 was injected at the end of the regular $16 \mathrm{~h}$ fasting period as a $10 \%$ solution in saline at a dose of $200 \mathrm{mg} / \mathrm{kg}$ body weight into the tail veins of mice under light ether anesthesia. Six mice were used per group. These mice were anesthetized with ether $18 \mathrm{~h}$ after Triton WR-1339 injection, and 1-1.5 $\mathrm{mL}$ of blood was drawn by cardiac puncture. Sera were obtained by centrifugation $(1500 \times \mathrm{g}, 10 \mathrm{~min})$. Tested samples, lovastatin or Xenical, were administered orally once a day for 3 days before Triton WR-1339 injection. The final administration of the samples was performed $1 \mathrm{~h}$ before Triton WR-1339 injection. Third, a hyperlipidemic mouse model based on high-fat diets was established. Mice were classified into 15 groups. Each group contained 6 mice. The high-fat control group was fed a highfat diet for 5 weeks. The normal group received a solid, normal diet. CF and RG were orally administered for 5 weeks at $50 \mathrm{mg} / \mathrm{kg} /$ day, ursolic acid and the ginsenoside $\mathrm{Rg} 3$ at $20 \mathrm{mg} / \mathrm{kg} /$ day, and xenical at $10 \mathrm{mg} / \mathrm{kg} /$ day. After a $16 \mathrm{~h}$ fasting period following the final administration of samples, blood samples were drawn by cardiac puncture under ether anesthesia.

\section{Determination of serum total cholesterol, triglycer- ide, and HDL cholesterol}

Total cholesterol was measured by the enzymatic method of Allain et al. (1974). Serum triglycerides were measured by the method designed by Kim et al. (2008). $\mathrm{HDL}$ cholesterol was measured by the enzymatic method of Kim et al. (2008).

\section{Statistical analysis}

All data are expressed as the mean \pm standard deviation, and statistical significance was analyzed by Student's $t$-test.

\section{RESULTS}

\section{In vivo antihyperlipidemic activity of $R G$ and $C F$}

We measured the hypolipidemic effects of RG and CF

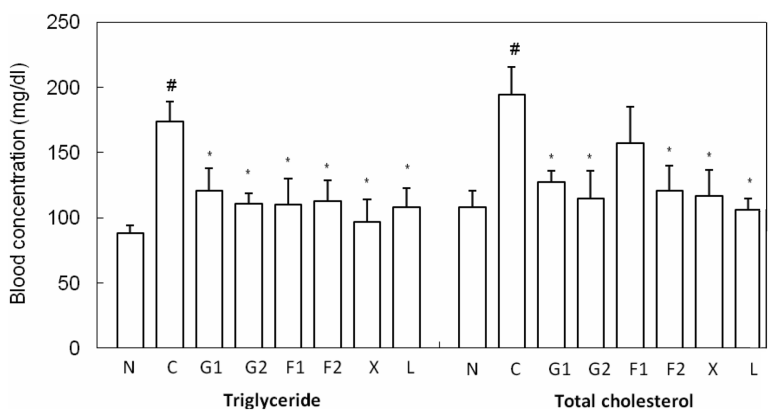

Fig. 1. Effect of red ginseng (RG), and Crataegii fructus (CF) in Trition WR-1339-induced Hyperlipidemic Mice. The normal group $(\mathrm{N})$ received a vehicle alone. The control group $(\mathrm{C})$ was treated with Triton WR-1339 alone. The samples were orally administered with Triton WR-1339: G1, $50 \mathrm{mg} / \mathrm{kg}$ red ginseng; $\mathrm{G} 2,100 \mathrm{mg} / \mathrm{kg}$ red ginseng; $\mathrm{F} 1,50 \mathrm{mg} / \mathrm{kg}$ Crataegii fructus; F2, $100 \mathrm{mg} / \mathrm{kg}$ Crataegii fructus; $X, 10 \mathrm{mg} / \mathrm{kg}$ Xenical; L, 10 $\mathrm{mg} / \mathrm{kg}$ lovastatin. Values indicate mean \pm S.D. $(\mathrm{n}=6)$.

\# Significantly different, compared with normal group $(p<0.05)$.

*Significantly different, compared with control group $(p<0.05)$.

on Triton WR-1339-induced hyperlipidemic mice (Fig. 1). Serum triglyceride (TG) and total cholesterol (TC) levels increased after treatment with Triton WR-1339. Treatment with RG or CF significantly reduced the Triton WR1339-induced increases. RG more potently reduced TC levels than CF, but CF more potently reduced TG levels than RG.

We also measured the inhibitory effects on corn-oilinduced hyperlipidemic mice (Fig. 2). Corn oil feeding significantly induced serum triglyceride levels, but not cho-

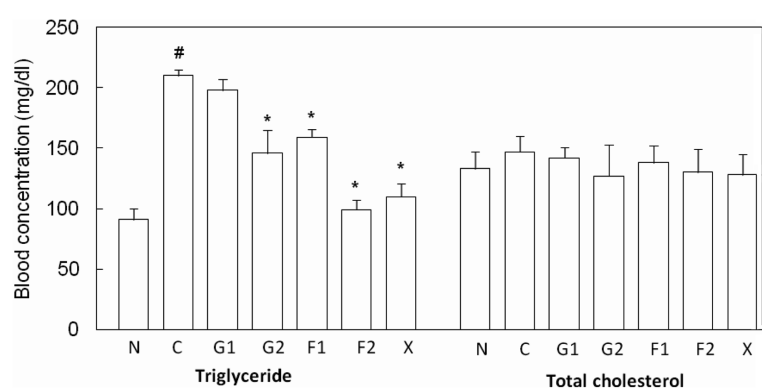

Fig. 2. Hypolipidemic Effect of red ginseng (RG), and Crataegii fructus (CF) in Corn Oil-induced Hyperlipidemic Mice. The normal group $(\mathrm{N})$ received a vehicle alone. The control group (C) was treated with corn oil alone. The samples were orally administered with corn oil: G1, $50 \mathrm{mg} / \mathrm{kg}$ red ginseng; G2, 100 $\mathrm{mg} / \mathrm{kg}$ red ginseng; F1, $50 \mathrm{mg} / \mathrm{kg}$ Crataegii fructus; F2, 100 $\mathrm{mg} / \mathrm{kg}$ Crataegii fructus; $X, 10 \mathrm{mg} / \mathrm{kg}$ Xenical. Values indicate mean \pm S.D. $(n=6)$.

\# Significantly different, compared with normal group $(p<0.05)$.

*Significantly different, compared with control group $(p<0.05)$. 


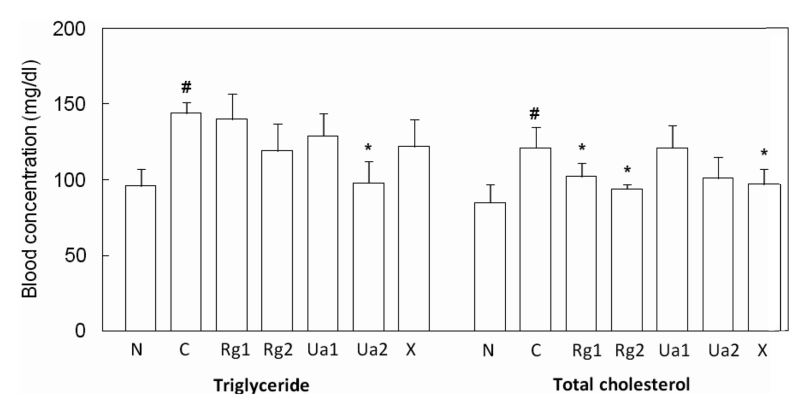

Fig. 3. Hypolipidemic Effect of Ginsenoside Rg3 and Ursolic Acid on Trition WR-1339-induced Hyperlipidemic Mice. The normal group $(\mathrm{N})$ received a vehicle alone. The control group (C) was treated with Triton WR-1339 alone. The samples were orally administered with Triton WR1339: $\mathrm{Rg} 1,10 \mathrm{mg} / \mathrm{kg}$ ginsenoside Rg3; Rg2, 25 mg/kg ginsenoside Rg3; Ua1, 10 mg/kg ursolic acid; Ua2, 25 mg/kg ursolic acid; X, 10 mg/kg Xenical. Values indicate mean \pm S.D. $(n=6)$.

\# Significantly different, compared with normal group $(p<0.05)$.

* Significantly different, compared with control group $(p<0.05)$.

lesterol levels. $R G$ and $C F$ treatment reduced serum $T G$ levels, but not back to control levels. CF was more potent than RG.

\section{In vivo antihyperlipidemic activity of Rg3 and urso- lic acid}

We measured the inhibitory activities of a representative component of $R G, R g 3$, and a represntative comursolic acid, in Triton WR-1339-induced hyperlipidemic mice (Fig. 3). TG and TC levels in serum were increased

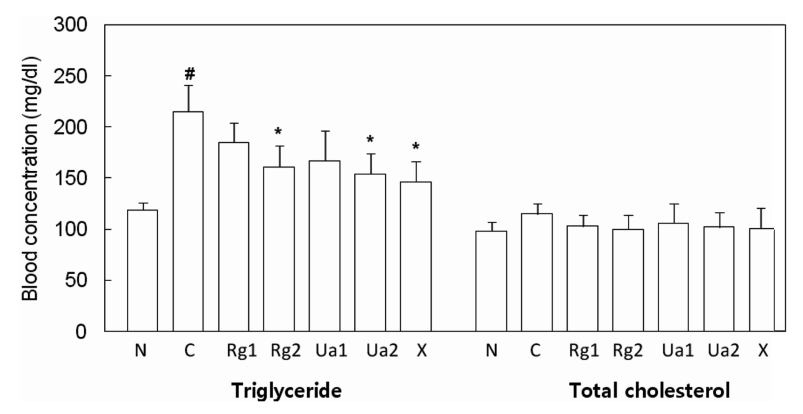

Fig. 4. Hypolipidemic Effect of Ginsenoside Rg3 and Ursolic Acid on Corn Oil-induced Hyperlipidemic Mice. The normal group $(\mathrm{N})$ received a vehicle alone. The control group $(\mathrm{C})$ was treated with corn oil alone. The samples were orally administered with corn oil: Rg1, 10 mg/kg ginsenoside Rg3; Rg2, 25 $\mathrm{mg} / \mathrm{kg}$ ginsenoside Rg3; Ua1, $10 \mathrm{mg} / \mathrm{kg}$ ursolic acid; Ua2, 25 $\mathrm{mg} / \mathrm{kg}$ ursolic acid; $X, 10 \mathrm{mg} / \mathrm{kg}$ Xenical. Values indicate mean \pm S.D. $(n=6)$.

\# Significantly different, compared with normal group $(p<0.05)$.

* Significantly different, compared with control group $(p<0.05)$. by treatment with Triton WR-1339, with Rg3 and ursolic acid treatment reducing those elevations. The TG level in the ursolic acid-treated group $(25 \mathrm{mg} / \mathrm{kg}$ ) was decreased more than in the Rg3-treated group, whereas Rg3 treatment reduced TC more than ursolic acid treatment. Rg3 and ursolic acid treatment also reduced hyperlipidemia levels in the corn oil treated group (Fig. 4). TG levels in the ursolic acid-treated group $(25 \mathrm{mg} / \mathrm{kg})$ were decreased more than the Rg3-treated group.
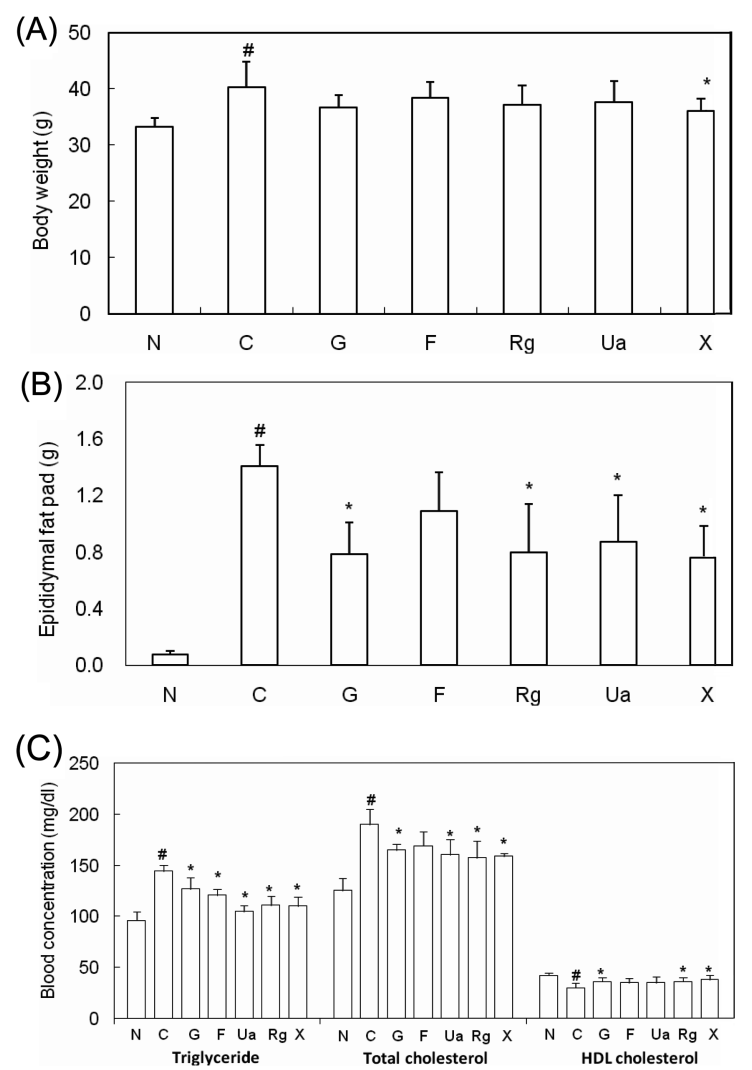

Fig. 5. Effect of red ginseng (RG), and Crataegii fructus (CF) on Body $(A)$ and Epididymal Fat $(B)$ Weights and Serum Triglyceride, Total cholesterol and High Density Lipoprotein (HDL) Cholesterol Levels (C) in Hyperlipidemic Mice Induced by High-Fat Diets. Each group contained 6 mice with body weights of $24.3 \pm 0.93 \mathrm{~g}$ (mean \pm standard deviation) per a mice. The normal group $(\mathrm{N})$ received a normal, solid diet. The control group (C) was fed the high-fat diet for 5 weeks, respectively. These agents were orally administered once a day with the high-fat diet for 5 weeks: G, $50 \mathrm{mg} / \mathrm{kg}$ red ginseng; F, 50 $\mathrm{mg} / \mathrm{kg}$ Crataegii fructus; Rg, $20 \mathrm{mg} / \mathrm{kg}$ ginsenoside Rg3; Ua, $20 \mathrm{mg} / \mathrm{kg}$ ursolic acid; X, $10 \mathrm{mg} / \mathrm{kg}$ Xenical. Body weight was measured before the final administration of the samples. Epididymal fat pads were taken under ether anesthesia and their weights were measured.

Values indicate mean \pm S.D.

\# Significantly different, compared with normal group $(p<0.05)$.

* Significantly different, compared with control group $(p<0.05)$. 
Table I. Inhibitory Effect of Red Ginseng (RG), Crataegii Fructus (CF), Ginsenoside Rg3 and Ursolic Acid for Pancreatic Lipase and HMG CoA Reductase Activities

\begin{tabular}{ccc}
\hline Samples & $\mathrm{IC}_{50}$ & $\mathrm{IC}_{50}$ \\
\cline { 2 - 3 } & $\begin{array}{c}\text { Pancreatic lipase } \\
(\mathrm{mg} / \mathrm{ml})\end{array}$ & $\begin{array}{c}\mathrm{HMG} \mathrm{CoA} \\
\text { reductase }(\mathrm{mg} / \mathrm{ml})\end{array}$ \\
\hline $\mathrm{RG}$ & 1.8 & 2 \\
$\mathrm{CF}$ & 1.6 & 5 \\
Ursolic acid & $0.9(1.7)^{\mathrm{a})}$ & $0.6(1.1)$ \\
Ginsenoside Rg3 & $1.5(2.1)$ & $0.2(0.3)$ \\
Xenical & $0.8(1.6)$ & $0.2(0.4)$
\end{tabular}

a) Values in parenthesis are those indicated in mmole for pancreatic lipase and $\mu$ mole for HMG CoA reductase.

\section{Effect of long-term feeding of RG and CF on high-fat diet-induced hyperlipidemia in mice}

We next measured the hypolipidemic effects of longterm feeding of RG, CF, and their constituents, $\mathrm{Rg} 3$ and ursolic acid, on high-fat diet-induced hyperlipidemic mice (Fig. 5). Triglyceride and total cholesterol levels in serum were increased by treatment with a high-fat diet for 5 weeks. RG, CF, and their constituents significantly decreased these levels. Ursolic acid $(20 \mathrm{mg} / \mathrm{kg})$ reduced TG levels the most potently, followed by Rg3 $(20 \mathrm{mg} / \mathrm{kg})$, and CF $(50 \mathrm{mg} / \mathrm{kg})$. Rg3 $(20 \mathrm{mg} / \mathrm{kg})$ reduced TC levels the most potently, followed by ursolic acid $(20 \mathrm{mg} / \mathrm{kg})$ and $R G(50 \mathrm{mg} / \mathrm{kg})$. These agents also were most potent at reducing the body and epididymal mass weights induced by the high-fat diet. Of them, RG most potently inhibit its increment.

\section{In vitro inhibitory effect of RG, CF, and their constit- uents on pancreatic lipase and HMG-CoA reductase activities}

To understand the hypolipidemic mechanism of RG and $C F$, we measured their inhibitory effects on pancreatic lipase and HMG-CoA reductase (Table 1). RG and $\mathrm{CF}$ all inhibited pancreatic lipase with similar potencies. However, their potencies against HMG-CoA reductase activity were different, with $\mathrm{Rg} 3$ the most potent, with an $\mathrm{IC}_{50}$ value of $2.1 \mathrm{mg} / \mathrm{mL}$ (triolein as a substrate), followed by ursolic acid and RG.

\section{DISCUSSION}

Hyperlipidemia can cause arteriosclerosis, hypertension, obesity, diabetes, and functional organ depression (Goldin et al., 1973). To cure hyperlipidemia, the inhibi- tors against pancreatic lipase, which is a key enzyme in lipid breakdown and is required to absorb fatty acids (Thomson et al., 1993), and HMG-CoA reductase, which catalyzes a key step in the mevalonate pathway, which is involved in the synthesis of sterols, isoprenoids, and other lipids (Espenshade and Hughes, 2007; Meigs et al., 1996) have been developed.

Xenical and statins have been developed. However, the repeated used of orlistat and lovastatin results in side effects (Davidson, 2003; Ballinger, 2000; Thompson Coon and Thompson Coon and Ernst et al., 2003). Therefore, many researchers have been studying the hypolipidemic effects of herbal medicines to develop them as alternative treatments for hyperlipidemia. However, the antihyperlipidemic effects of RG and CF have not been thoroughly studied. Here, RG and CF, as well as their constituents had antihyperlipidemic effects on corn oil-, Trition WR1339- and high-fat diet-induced hyperlipidemic mice. RG more potently reduced total blood cholesterol levels than $\mathrm{CF}$, whereas $\mathrm{CF}$ more potently reduced total triglyceride levels than $R G$. The ginsenoside Rg3 and ursolic acid, the primary constituents of RG and $\mathrm{CF}$, also potently reduced blood total cholesterol and triglyceride levels. Compared with the parent agents, Rg3 more potently reduced total cholesterol levels, and ursolic acid more potently reduced total triglyceride levels. The inhibitory effect of Rg3 is comparable with that of lovastatin, which is a potent inhibitor for HMG-CoA reductase. The inhibitory effect of ursolic acid is comparable with that of Xenical, which is a potent inhibitor for pancreatic lipase.

In hyperlipidemic mice induced by long-term feeding of high fat, RG and CF and their constituent lowered blood total cholesterol and triglyceride levels as well as body and epididymal mass weights. Particularly, RG and Rg3 reduced total blood cholesterol levels more than ursolic acid; however, ursolic acid lowered blood triglyceride levels more than Rg3. RG and CF all inhibited pancreatic lipase and HMG CoA reductase activities. CF and its constituent ursolic acid more potently inhibited pancreatic lipase activity than $R G$. $R G$ and its constituent $R g 3$ more potently inhibited HMG-CoA reductase activity than ursolic acid, which is a main constituent of CF. These results suggest that the antihyperlipidemic effect of RG, particularly the ginsenoside Rg3, may be due to inhibition of HMG CoA reductase rather than pancreatic lipase, and that the effects of CF, particularly ursolic acid, may be due to inhibition of pancreatic lipase more than HMGCoA reductase. These findings suggest that $R G$ and $C F$ 
may be suitable for the therapies of hypercholesterolemia and triglyceridemia, respectively.

\section{REFERENCES}

Allain, C. C., Poon, L. S., Chan, C. S. G., Richmond, W. and Fu, P. C.(1974). Enzymatic determination of total serum cholesterol. Clin. Chem. 20, 470-475.

Bae, E. A., Han, M. J., Choo, M. K., Park, S. Y. and Kim, D. $\mathrm{H} .(2002)$. Metabolism of 20(S)- and 20(R)-ginsenoside Rg3 by human intestinal bacteria and its relation to in vitro biological activities. Biol. Pharm. Bull. 25, 58-63.

Ballinger, A. (2000). Orlistat in the treatment of obesity. Expert. Opin. Pharmacother. 1, 841-847.

Birari, R. B. and Bhutani, K. K. (2007). Pancreatic lipase inhibitors from natural sources: unexplored potential. Drug Discovery Today 12, 879-889.

Carey, M. C., Small, D. M. and Bliss, C. M. (1993). Lipid digestion and absorption. Annu. Rev. Physiol. 45, 651-677.

Chang, W. T., Dao, J., Shao, Z. H. (2005). Hawthorn: potential roles in cardiovascular disease. Am. J. Chin. Med. 33, 1-10.

Davidson, M. H. (2003). Ezetimibe: a novel option for lowering cholesterol. Expert. Rev. Cardiovasc. Ther. 1, 11-21.

Duhault, J., Boulanger, M., Beregi, L., Sicot, N., Bouvier, F. (1976). 780 SE: a new type of hypolipemic agent. Atherosclerosis, 23, 63-72.

Edwards, P. A., Lemongello, D. and Fogelman, A. M. (1979). Improved methods for the solubilization and assay of hepatic 3-hydroxy-3-methylglutaryl coenzyme A reductase. J. Lipid Res. 20, 40-46.

Edwards, P. A., Lemongello, D. and Kane, J. (1980). Properties of purified rat hepatic 3-hydroxy-3-methylglutaryl coenzyme A reductase and regulation of enzyme activity. J. Biol. Chem. 255, 3715-3725.

Endo, A. (1992). The discovery and development of HMG-CoA reductase inhibitors. J. Lipid Res. 33, 1569-1582.

Espenshade P. J., Hughes A. L. (2007). Regulation of sterol synthesis in eukaryotes. Annu. Rev. Genet. 41, 401-427.

Goldstein, J. L., Schrott, H., Hazzard, E., Bierman, E. and Motuski, A. (1973). Hyperlipidemia in coronary heart disease. I. Lipid levels in 500 survivors of myocardial infarction. J. Clin. Invest. 52, 1544-1568.

Heber, D. (2001). Herbs and atherosclerosis. Curr. Atheroscler. Rep. 3, 93-96.
Heller, R. A. and Shrewsburg, M. A. (1976). 3-Hydroxy-3-methylglutaryl coenzyme A reductase from rat liver. Its purification, properties, and immunochemical studies. J. Biol. Chem. 251, 3815-3822.

la Cour, B., Molgaard, P., Yi, Z. (1995). Traditional Chinese medicine in treatment of hyperlipidaemia. J. Ethnopharmacol. 46, 125-129 (1995). .

Inoue, M., Wu C.Z., Dou D.Q., Chen Y.J., Ogihara Y. (1999). Lipoprotein lipase activation by red ginseng saponins in hyperlipidemia model animals. Phytomedicine 6, 257-265.

Kim H. Y., Jeong da, M., Jung, H. J., Jung, Y. J., Yokozawa, T. and Choi, J. S. (2008). Hypolipidemic effects of Sophora flavescens and its constituents in poloxamer 407-induced hyperlipidemic and cholesterol-fed rats. Biol. Pharm. Bull. 31, 73-78.

Liu, J. (1995). Pharmacology of oleanolic acid and ursolic acid. J. Ethnopharmacol. 49, 57-68.

Meigs, T. E., Roseman, D. S. and Simoni, R. D. (1996). Regulation of 3-hydroxy-3-methylglutaryl-coenzyme $A$ reductase degradation by the nonsterol mevalonate metabolite farnesol in vivo. J. Biol. Chem. 271, 7916-7922

Thomson, A. B., Schoeller, C., Keelan, M., Smith, L. Clandinin M. T. (1993). Lipid absorption: passing through the unstirred layers, brush-border membrane, and beyond. Can. J. Physiol. Pharmacol. 71, 531-555.

Thompson Coon J. S. and Ernst E. (2003). Herbs for serum cholesterol reduction: a systematic view. J. Fam. Pract. 52, 468-478

Trinh, H. T., Han, S. J., Kim, S. W., Lee, Y. C. and Kim, H. D. (2007). Bifidus fermentation increases hypolipidemic and hypoglycemic effects of red ginseng. J. Microbiol. Biotechnol. 17, 1127-1133.

White, L. W. and Rudney, H. (1970). Regulation of 3-hydroxy-3methylglutarate and mevalonate biosynthesis by rat liver homogenates. Effects of fasting, cholesterol feeding, and triton administration. Biochemistry 9, 2725-2731.

Zhou, L., Zuo, Z. and Chow, M. S. (2005). Danshen: an overview of its chemistry, pharmacology, pharmacokinetics, and clinical use. J. Clin. Pharmacol. 45, 1345-1359.

Kusama, H., Nishiyama, M. and lkeda, S. (1988). Pharmacological investigation of bezafibrate, a hypolipidemic agent (1). Effects of bezafibrate on normal and experimental hyperlipidemia in rats. Folia Pharmacol. Jpn. 92, 175-180

Sardesai V.M. and Mannig J.A., The determination of triglycerides in plasma and tissues. Clin. Chem. 14, 156-158. 